\title{
APPLICATION OF AN ELASTOPLASTIC MODEL TO PREDICT BEHAVIORS OF CONCRETE-FACED ROCK-FILL DAM UNDER COMPLEX LOADING CONDITIONS
}

\author{
Kuangmin $\mathrm{WEI}^{\mathrm{a}}$, Sheng ZHU \\ ${ }^{a}$ Geotechnical Engineering Department, Nanjing Hydraulic Research Institute, \\ Nanjing 210024, Jiangsu, China \\ ${ }^{b}$ Research Institute of Hydraulic Structures, Hohai University, 210098, Nanjing, China
}

Received 02 Oct 2012; accepted 02 Oct 2012

\begin{abstract}
In this research, a simplified rotational kinematic hardening model with the concept of sub-loading was used to predict behaviors of Concrete-Faced Rock-fill Dam under complex loading conditions. The model can overcome the shortcomings of classic elastoplastic model (i.e. soil behaviors under cyclic loading-unloading can be predicted). Elastoplastic formula of the model was presented in detail. Then this model was verified with test results of coarse grained soils, under both monotonic loading and cyclic loading-unloading conditions. This model was also applied to analyze deformation of Shuibuya rock-fill dam, computed results and in-situ measurements are compared. Results showed that computed results were consistent with in-situ measurements in both construction and operation period. Results also showed that permanent deformation that was caused by fluctuations of the reservoir level can also be predicted by this rotational kinematic hardening model.
\end{abstract}

Keywords: elastoplastic model, coarse grained soils, sub-loading surface, rotational kinematic hardening rule, ConcreteFaced Rock-fill Dam.

\section{Introduction}

Concrete-Faced Rock-fill Dam (CFRD) is a typical structure filled with coarse grained soils. These materials span a wide particle size range; mechanical properties of coarse grained soils are more complex than sand or clay for their strong particle breakage and irregular shapes. In past years, several elastoplastic models were proposed to describe the behaviors of the coarse grained soils. Shen $(1986,1994)$ introduced a two-yield-surface model for coarse grained soils, which is widely used in rock-fill dam analysis for its simplicity and practicality; Alonso et al. (1990, 2005) and Alonso (2007) proposed Barcelona Basic Model (BBM) and Rock-fill Model (RM), which were also applied to analyze of Beliche Dam. These models could give satisfying description of coarse grained soils' behaviors under monotonic loading; however, they are incapable of predicting soils' behaviors under complex loading conditions (e.g. loading-unloading and cyclic loadings conditions).

Conventional plasticity theories assume that the domain enclosed by the yield surface is totally elastic, thus only elastic deformation could occur within the yield surface. Plastic deformation would not generate during the unloading and loading process until the stress penetrates the current yield surface. However, many test results (Wang et al. 1990; Niemunis et al. 2005) indicated that large stress reversals in particle materials result in plastic deformation (e.g. in the process of unloading and reloading, a stress-strain curve with a closed hysteresis loop will form). Currently, there is a tendency to extend plasticity theory to reflect this part of plastic deformation within the yield surface.

Soil elements in CFRD experience complex loadings (cyclic loading-unloading) when the reservoir level fluctuates. This situation is especially common in a pumped storage power station, of which reservoir level fluctuates more frequently. As an example, in-situ measuring records of Tongbo pumped storage power station (Xu 2008) are shown in Figure 1(a) and (b).

Obviously, settlements of the dam increase with the fluctuations of reservoir level. Other factors (e.g. rheological effect) may also lead to continuous deformation of CFRD, but in Figure 1(b), variations of vertical displacement are closely related to water level. Therefore, fluctuations of water level play a major role in deformation of the CFRD. However, elastoplastic model in the framework of classic plasticity theories cannot reflect this part of permanent deformation (plastic deformation),

Corresponding author: Kuangmin Wei

E-mail: weikuangming2341@163.com 


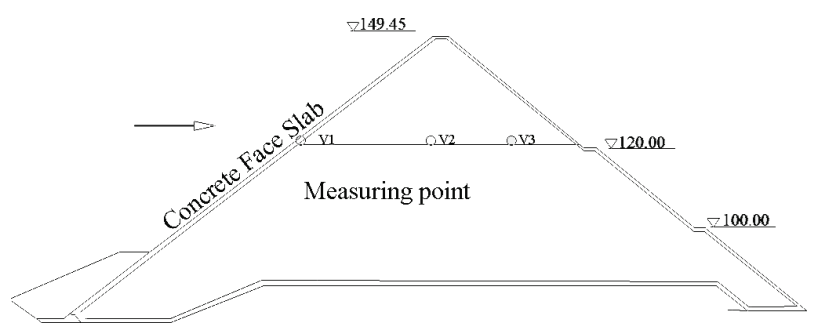

(a) Positions of displacement gauges

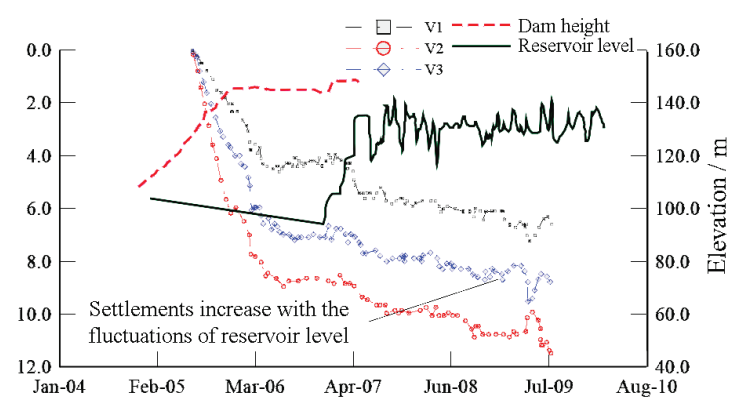

(b) Settlements increase with the fluctuations of water level

Fig. 1. Settlement measurements and fluctuations of water level (Tongbo dam, Xu 2008)

because in this process, stress state of each soil element is always within its yield surface (in other words, the current state of stress does not exceed its maximum historical stress).

In order to reflect the plastic strain that occurs within yield surface, the concept of "bounding surface" was introduced by Dafalias (1986a, b), which was also called "sub-loading surface" by Hashiguchi (1980, 2005), Hashiguchi et al. (2005) and Hashiguchi and Ozakib (2008). After the concept of "sub-loading surface" was introduced into soil mechanics, several elastoplastic models were developed based on these theories. Nakai and Hinokio (2004) expanded the $t_{i j}$-clay model with the concept of "sub-loading surface" to reflect the influence of density or confining pressure on deformation and strength of the soils. Yao et al. (2007) applied the concept of "subloading surface" to a so-called "UH" model to describe the overconsolidated behaviors of soils. Pedroso and Farias (2011) extended the Barcelona Basic Model (BBM) for unsaturated soil under cyclic loading with the concept of "sub-loading surface".

This paper simplified the model proposed by Yao et al. (2011), which combines the sub-loading concept with the rotational kinematic hardening rule. Plasticity formula of this model is given in detail. Test results of coarse grained soils were used to validate this model. Results showed that the model could simulate the behaviors of coarse grained soils under both monotonic loading and complex loadings. Then this model was applied to analyze deformation of Shuibuya CFRD, computed results and in-situ measurements were compared, permanent deformation of the dam that is caused by fluctuations of water level was also predicted.

\section{Sub-loading surface model with rotational hardening rule}

\subsection{Yield surface of the elastoplastic model}

Yao et al. $(2008,2011)$ proposed a model to simulate mechanical behaviors of sand considering particle breakage. Yao et al. (2011) developed this model within the concept of sub-loading; yield surface of this model was transformed into an ellipse by stress space transition (Yao et al. 2004). However, elastoplastic matrix will not be symmetrical after stress space transition, which increases the complexity in numerical calculation. In this paper, after adopting the associated flow rule, the yield surface or plastic potential surface is written into the following form:

$$
\begin{aligned}
& f=g=\left(c_{t}-c_{e}\right)\left(\frac{p_{c}}{p_{a}}\right)^{\frac{m n}{n+1}} . \\
& \left\{\left[\frac{p}{p_{a}}\left(1+\frac{\eta^{* 2}}{M^{2}-\zeta^{2}}\right)\right]^{\frac{m}{n+1}}-\left(\frac{p_{0}}{p_{a}}\right)^{\frac{m}{n+1}}\right\}-H,
\end{aligned}
$$

where: $c_{t}$ is the compression index; $c_{e}$ is the swelling index; $m$ is a coefficient for soils; $p_{0}$ is the initial mean stress; $p_{a}$ is the atmospheric pressure, $H$ is the hardening parameter; $c_{t}, c_{e}, m, p_{0}$ define the isotropic compression law of coarse grained soils in the following form:

$$
\varepsilon_{v}^{p}=\left(c_{t}-c_{e}\right)\left[\left(\frac{p}{p_{a}}\right)^{m}-\left(\frac{p_{0}}{p_{a}}\right)^{m}\right] .
$$

Strength of the coarse grained soils is defined as:

$$
M_{f}=M\left(\frac{p}{p_{c}}\right)^{-n}
$$

where $M, n, p_{c}$ are material parameters.

The mean stress $p$ and general shear stress $q$ are defined as:

$$
p=\frac{1}{3}\left(\sigma_{1}+\sigma_{2}+\sigma_{3}\right)
$$

$q=\frac{1}{\sqrt{2}}\left[\left(\sigma_{1}-\sigma_{2}\right)^{2}+\left(\sigma_{2}-\sigma_{3}\right)^{2}+\left(\sigma_{3}-\sigma_{1}\right)^{2}\right]^{1 / 2}$.

The other variables involved in Eqn (1) are defined as:

$$
\begin{gathered}
\eta^{*}=\sqrt{\frac{3}{2}\left(\eta_{i j}-\beta_{i j}\right)\left(\eta_{i j}-\beta_{i j}\right)} ; \\
\eta_{i j}=\frac{\sigma_{i j}-p \delta_{i j}}{p} ; \\
\varsigma=\sqrt{\frac{3}{2} \beta_{i j} \beta_{i j}} ; \\
\eta=q / p,
\end{gathered}
$$

where: $\beta_{i j}$ is the anisotropic stress tensor; $\sigma_{i j}$ is the stress tensor; $\delta_{i j}$ is the Kronecker delta. The Einstein convention of summation over repeated indices is used. 
According to results of Zhang et al. (2007), evolution rule for stress-induced stress tensor $\beta_{i j}$ is defined as:

$$
d \beta_{i j}=\sqrt{3 / 2} \frac{M}{c_{t}-c_{e}}\left(m_{b} M-\zeta\right) d \varepsilon_{s}^{p} \frac{\eta_{i j}-\beta_{i j}}{\eta^{*}},
$$

where $m_{b}$ is a material parameter, and:

$\varepsilon_{s}^{p}=\frac{\sqrt{2}}{3}\left[\left(\varepsilon_{1}^{p}-\varepsilon_{2}^{p}\right)^{2}+\left(\varepsilon_{2}^{p}-\varepsilon_{3}^{p}\right)^{2}+\left(\varepsilon_{3}^{p}-\varepsilon_{1}^{p}\right)^{2}\right]^{1 / 2}$.

With the rotational hardening strategy, a closed hysteresis loop can form in a loading-unloading cycle (Lade, Inel 1997; Hashiguchi, Chen 1998).

Yield surfaces are presented in Figure 2. As can be seen, flat ratio of the elliptical yield surface changes with $\zeta$. The larger of $\zeta$ is, the "thinner" of the yield surface.

\subsection{Hardening rule of the model}

Yao et al. (2007) developed a so-called unified hardening parameter for both clay and sand; this unified hardening parameter is also used in the present model. However, the original unified hardening parameter is only limited to isotropic hardening. After adopting the rotational hardening rule, another term should be added. Finally, the hardening parameter $H$ is expressed as:

$$
d H=\frac{M^{4}}{M_{f}^{4}} \frac{M_{f}-\eta^{4}}{M-\eta^{4}} d \varepsilon_{v}^{p}+\frac{\eta}{M} \frac{\partial f}{\partial \beta_{i j}} d \beta_{i j},
$$

where the plastic volumetric strain is defined as:

$$
\varepsilon_{v}^{p}=\varepsilon_{1}^{p}+\varepsilon_{2}^{p}+\varepsilon_{3}^{p} .
$$

\subsection{Development of this model with the concept of sub-loading}

\subsubsection{Current yield surface and reference yield surface}

The sub-loading model consists of two yield surfaces (current yield surface and reference yield surface). Current yield surface in this paper is similar to Eqn (1), i.e.:

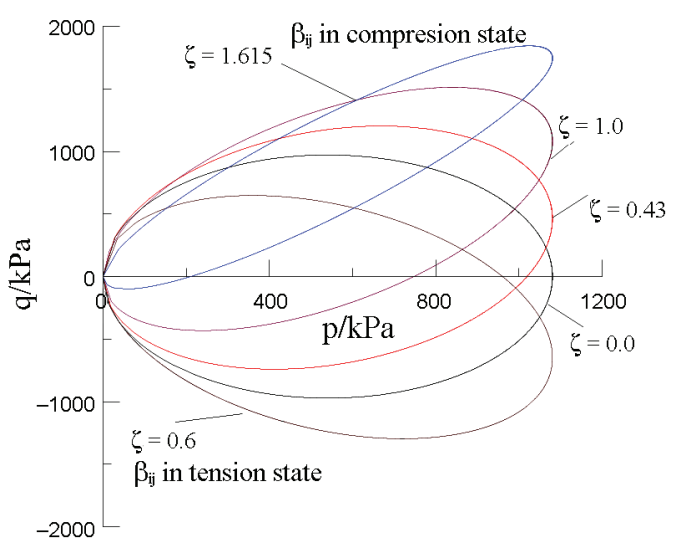

Fig. 2. Shapes of yield surface change with $\zeta$

$$
\begin{aligned}
& f=\left(c_{t}-c_{e}\right)\left(\frac{p_{c}}{p_{a}}\right)^{\frac{m n}{n+1}} \cdot \\
& \left\{\left[\frac{p}{p_{a}}\left(1+\frac{\eta^{* 2}}{M^{2}-\zeta^{2}}\right)\right]^{\frac{m}{n+1}}-\left(\frac{p_{0}}{p_{a}}\right)^{\frac{m}{n+1}}\right\}-f_{c}=0,
\end{aligned}
$$

which always passes through the current stress state $(p, q)$.

The reference yield surface is expressed as:

$$
\begin{aligned}
& \bar{f}=\left(c_{t}-c_{e}\right)\left(\frac{p_{c}}{p_{a}}\right)^{\frac{m n}{n+1}} \cdot \\
& \left\{\left[\frac{\bar{p}}{p_{a}}\left(1+\frac{\eta^{* 2}}{M^{2}-\zeta^{2}}\right)\right]^{\frac{m}{n+1}}-\left(\frac{p_{0}}{p_{a}}\right)^{\frac{m}{n+1}}\right\}-\bar{H}=0,
\end{aligned}
$$

on which the reference stress point $(\bar{p}, \bar{q})$ is located. The size of the reference yield surface is determined by hardening rule, as discussed in section 2.2. Therefore, an Over-Consolidated (OC) parameter $R$ is defined by Eqn (14):

$$
\begin{aligned}
& R=\frac{p}{p}=\frac{p}{p_{a}}\left(1+\frac{\eta^{* 2}}{M^{2}-\zeta^{2}}\right) / \\
& {\left[\frac{\bar{H}}{c_{t}-c_{e}}\left(\frac{p_{c}}{p}\right)^{-\frac{m n}{n+1}}+\left(\frac{\bar{p}_{0}}{p_{a}}\right)^{\frac{m}{n+1}}\right]^{\frac{n+1}{m}},}
\end{aligned}
$$

which indicates the "mapping rule"; point $\bar{A}$ is the "image point" of the current stress state (point $A$ ) on reference surface, shown in Figure 3.

\subsubsection{Potential strength of coarse grained soils}

In Eqn (3), strength of coarse grained soils is expressed as a function of the mean stress $p$, this expression is only limited to soils with $R=1.0$. However, a general formula for soils is given in Eqn (15):

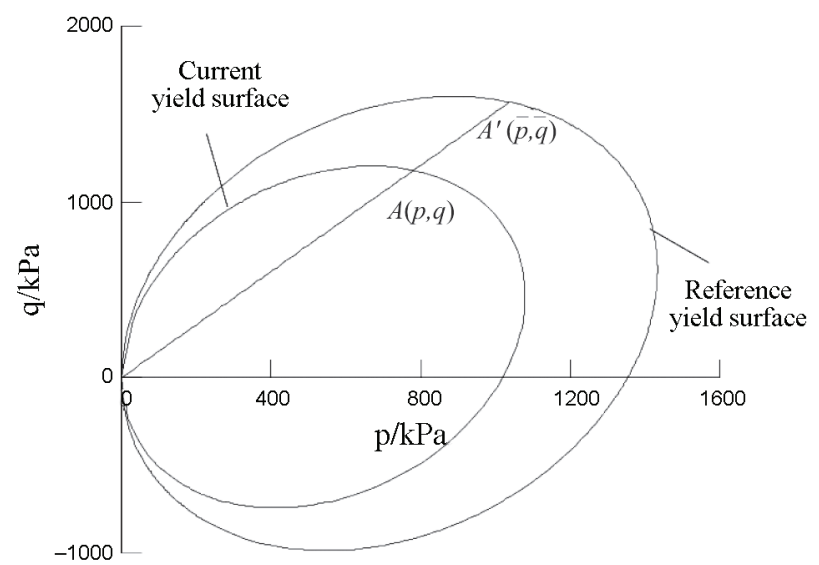

Fig. 3. Current yield surface and reference yield surface 


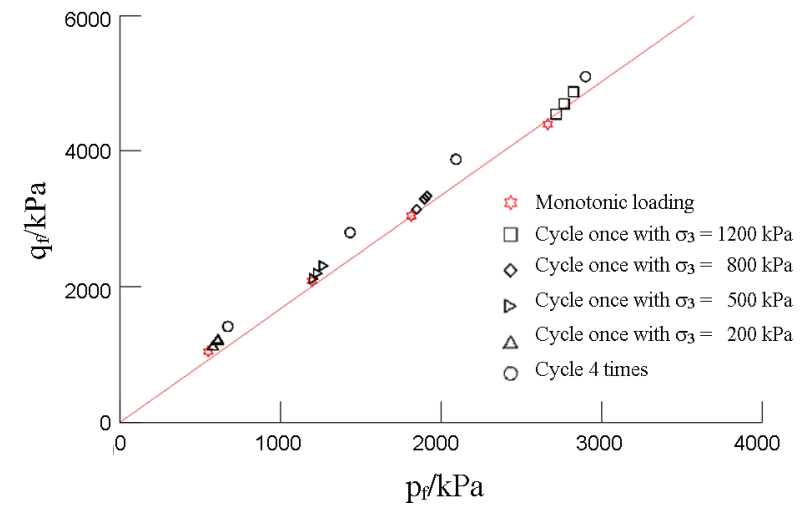

Fig. 4. Stress state at failure with samples experience different load paths

$$
\begin{gathered}
M_{f}^{p}=6[\sqrt{k(1+k)}-k] \\
k=\frac{M_{f}^{2}}{12 \cdot\left(3-M_{f}\right) R^{\alpha}} .
\end{gathered}
$$

Eqn (15) is deduced according to Hvorslev's theories (Yao et al. 2012); $\alpha$ is a material parameter to control the value of potential strength. Until now, it is hard to validate Hvorslev's theories with coarse grained soils, because it is hard to make the state of coarse grained soils corresponding to the remolded normally consolidated clay (Nakai, Hinokio 2004), but shear strength of coarse grained soils indeed increased after loading-unloading cycle. This phenomenon is confirmed with test data in this paper (Fig. 4), as will be discussed later. Therefore, Eqn (15) is used in this study preliminarily.

\section{Elastoplastic formula of the rotational hardening model}

Elastic modulus is expressed in the following form, and the Poisson's ratio $v$ is assumed to be constant 0.3 :

$$
E=\frac{3(1-2 v) p_{a}^{m}}{m C_{e} p^{m-1}}
$$

Following the associated flow rule, the plastic strain increment can be expressed as:

$$
d \varepsilon_{i j}^{p}=\Lambda \frac{\partial g}{\partial \sigma_{i j}}=\Lambda \frac{\partial f}{\partial \sigma_{i j}}
$$

in which, $\Lambda$ is the plastic multiplier.

Differentiating Eqn (13) and substituting Eqn (9), Eqn (17) into it:

$$
\begin{aligned}
& d F=\frac{\partial f}{\partial \sigma_{i j}} d \sigma_{i j}+\Lambda\left(1-\frac{\eta}{M}\right) \sqrt{3 / 2} \frac{M}{c_{t}-c_{e}}\left(m_{b} M-\zeta\right) . \\
& \frac{\partial f}{\partial \beta_{i j}} \frac{\eta_{i j}-\beta_{i j}}{\eta^{*}} \sqrt{\frac{\partial f}{\partial S_{m n}} \frac{\partial f}{\partial S_{m n}}}- \\
& \Lambda \frac{M^{4}}{M_{f}^{p 4}} \frac{M_{f}^{p}-\eta^{4}}{M-\eta^{4}} \frac{\partial f}{\partial \sigma_{m m}}=0 .
\end{aligned}
$$

Since:

$$
d \sigma_{i j}=C^{e}\left(d \varepsilon_{i j}-d \varepsilon_{i j}^{p}\right)=C^{e}\left(d \varepsilon_{i j}-\Lambda \frac{\partial f}{\partial \sigma_{i j}}\right),
$$

where: $C^{e}$ is the elastic matrix; $S_{i j}$ is the deviatoric part of stress tensor.

Make:

$$
\begin{gathered}
\psi=\sqrt{3 / 2} \frac{M}{c_{t}-c_{e}}\left(m_{b} M-\zeta\right)\left(1-\frac{\eta}{M}\right) ; \\
\Omega=\frac{M^{4}}{\left(M_{f}^{p}\right)^{4}} \frac{M_{f}^{p}-\eta^{4}}{M-\eta^{4}} .
\end{gathered}
$$

According to Eqn (18), we get:

$$
\Lambda=\frac{\frac{\partial f}{\partial \sigma_{i j}} C^{e} d \varepsilon_{i j}}{\frac{\partial f}{\partial \sigma_{i j}} C^{e} \frac{\partial f}{\partial \sigma_{i j}}+\Omega \frac{\partial f}{\partial \sigma_{m m}}-\psi \frac{\partial f}{\partial \beta_{i j}} \frac{\eta_{i j}-\beta_{i j}}{\eta^{*}} \sqrt{\frac{\partial f}{\partial S_{m n}} \frac{\partial f}{\partial S_{m n}}}} .
$$

It is easy to obtain the following relations:

$$
\begin{gathered}
\frac{\partial f}{\partial \sigma_{i j}}=\frac{\partial f}{\partial p} \frac{\partial p}{\partial \sigma_{i j}}+\frac{\partial f}{\partial \eta^{*}} \frac{\partial \eta^{*}}{\partial \sigma_{i j}} \\
\frac{\partial f}{\partial p}=\left(c_{t}-c_{e}\right)\left(\frac{p_{c}}{p_{a}}\right)^{\frac{m n}{n+1}} \frac{m}{n+1} . \\
\left(1+\frac{\eta^{* 2}}{M^{2}-\zeta^{2}}\right)^{\frac{m}{n+1}}\left(\frac{p}{p_{a}}\right)^{\frac{m}{n+1}-1} \frac{1}{p_{a}} \\
\frac{\partial f}{\partial \eta^{*}}=\left(c_{t}-c_{e}\right)\left(\frac{1}{3} \delta_{i j} ;\right. \\
\left.\frac{m}{p_{a}}\right)^{\frac{m n}{n+1}}\left(\frac{p}{p_{a}}\right)^{\frac{m}{n+1}} . \\
\left(1+\frac{\eta^{* 2}}{M^{2}-\zeta^{2}}\right)^{\frac{m}{n+1}-1}\left(\frac{2 \eta^{*}}{M^{2}-\zeta^{2}}\right)
\end{gathered}
$$

$$
\begin{aligned}
\frac{\partial \eta^{*}}{\partial \sigma_{i j}}= & \frac{1}{2 \eta^{*} p}\left[3\left(\eta_{i j}-\beta_{i j}\right)-\eta_{m n}\left(\eta_{m n}-\beta_{m n}\right) \delta_{i j}\right] \\
& \sqrt{\frac{\partial f}{\partial S_{i j}} \frac{\partial f}{\partial S_{i j}}}=\left(c_{t}-c_{e}\right) \frac{m}{n+1}\left(\frac{p_{c}}{p_{a}}\right)^{\frac{m n}{n+1}} \cdot \\
& \left(\frac{p}{p_{a}}\right)^{\frac{m}{n+1}} \cdot\left(1+\frac{\eta^{* 2}}{M^{2}-\zeta^{2}}\right)^{\frac{m}{n+1}-1} \cdot \\
& \left(\frac{1}{p}\right)\left(\frac{\sqrt{6}}{M^{2}-\zeta^{2}}\right) \eta^{*}\left(1+\frac{\eta^{* 2}}{M^{2}-\zeta^{2}}\right)^{\frac{m}{n+1}-1} . \\
& \left(\frac{1}{p}\right)\left(\frac{\sqrt{6}}{M^{2}-\zeta^{2}}\right) \eta^{*} ;
\end{aligned}
$$




$$
\begin{aligned}
& \frac{\partial f}{\partial \beta_{i j}}=\left(c_{t}-c_{e}\right) \frac{m}{n+1}\left(\frac{p_{c}}{p_{a}}\right)^{\frac{m n}{n+1}} . \\
& \left(\frac{p}{p_{a}}\right)^{\frac{m}{n+1}}\left(1+\frac{\eta^{* 2}}{M^{2}-\zeta^{2}}\right)^{\frac{m}{n+1}-1} . \\
& \left(\frac{1}{M^{2}-\zeta^{2}}\right)\left\{-3\left(\eta_{i j}-\beta_{i j}\right)+3 \beta_{i j} \eta^{* 2}\left(\frac{1}{M^{2}-\zeta^{2}}\right)\right\} .
\end{aligned}
$$

\section{Test results of coarse grained soils and model predictions}

Drained triaxial tests are conducted using granite rockfills, particle size distribution of testing materials is shown in Figure 5. Dry density of the sample is $1.97 \mathrm{~g} / \mathrm{cm}^{3}$, shear rate is set to $0.1 \sim 0.5 \% / \mathrm{min}$. These tests are conducted in Hohai University (Chu 2011).

\subsection{Determination of model parameters}

The following nine parameters are used in the rotational kinematic model: $c_{t}, c_{e}, m, M, p_{c}, n, v, m_{b}, \alpha$, all of which can be determined via conventional test except for $v$ The value of $v$ is assumed to be 0.3 .

Parameters $c_{t}, c_{e}, m$ could be determined directly via isotropic compression line and its swell line in $e-p$ plane according to Eqn (2) (Yao et al. 2008). However, for coarse grained soils, effects of "membrane penetration" may lead to a rather large error in measuring the volumetric strain. Therefore, in practice, $c_{t}, c_{e}, m$ are back calculated from monotonic loading triaxial tests curves using Immune Genetic Algorithm (IGA).

$M, p_{c}, n$ can be determined via fitting the strength of coarse grained soils in monotonic loading conventional triaxial tests, strength parameters of granite rock-fills is shown in Figure 6.

Parameter $\alpha$ is an empirical parameter used to describe the rate of volume change under cyclic loadings. Parameter $m_{b}$ is the limitation of rotation of yield surface. Both of them can be determined by fitting the hysteresis loop in a loading-unloading cycle (Yao et al. 2011).

As a result, model parameters of granite rock-fills are listed in Table 1.

\subsection{Monotonic loading}

Conventional triaxial tests results and model predictions are compared in Figure 7. As can be seen, this model could describe behaviors of coarse grained soils under monotonic loading well. Coarse grained soils tend to dilate in low confining pressure, while in high confining pressure, dilatancy disappears gradually.

Table 1. Parameters of the rotational hardening model

\begin{tabular}{cccccccc}
\hline$C_{t}$ & $C_{e}$ & $m$ & $M$ & $p_{c}(\mathrm{kPa})$ & $n$ & $m_{b}$ & $\alpha$ \\
\hline 0.0068 & 0.0012 & 0.60 & 1.62 & 5000.0 & 0.098 & 0.65 & 1.0 \\
\hline
\end{tabular}

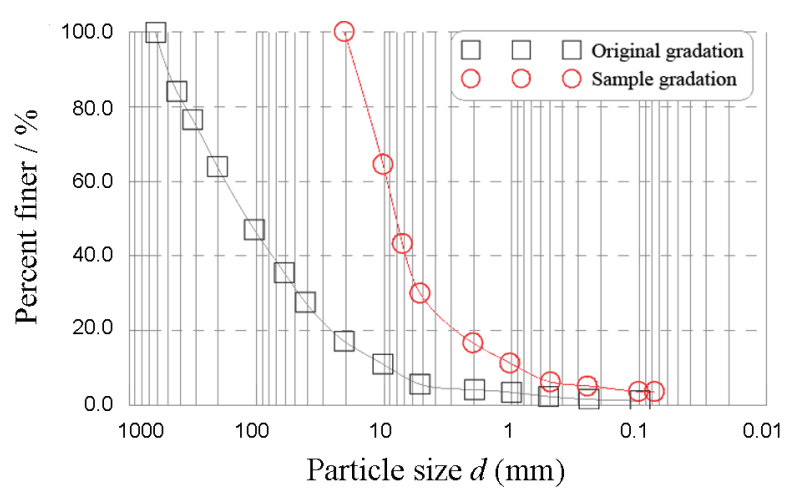

Fig. 5. Particle size distribution of testing soils

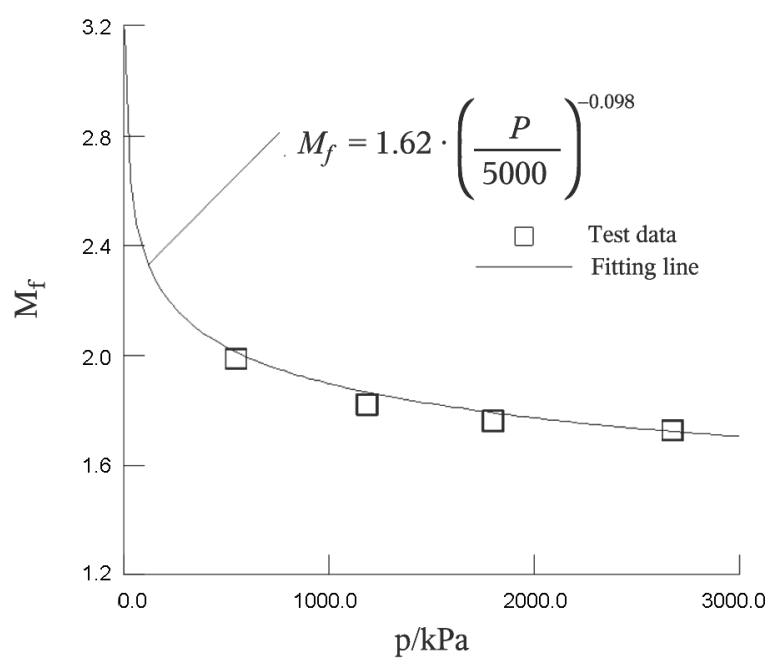

Fig. 6. Strength parameters of the granite rock-fills

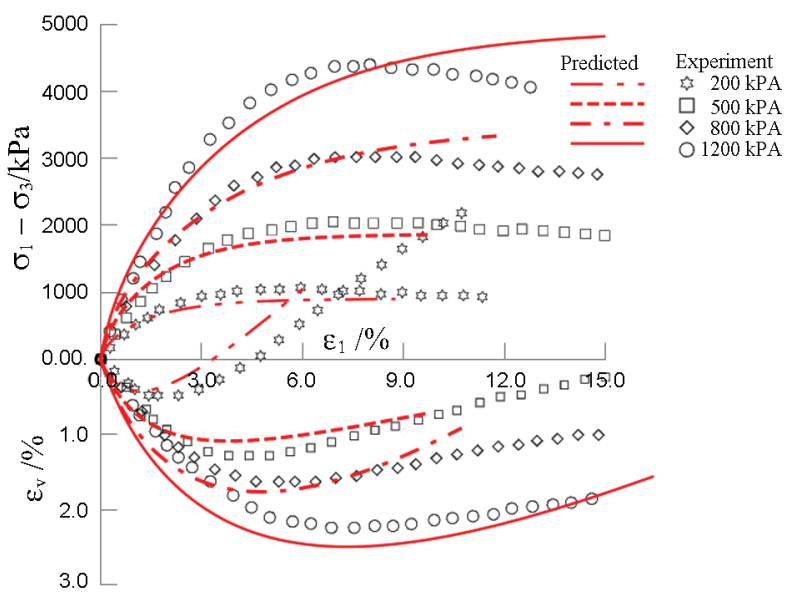

Fig. 7. Comparison between test results and model predictions under monotonic loading

\subsection{Predictions under loading-unloading cycles}

Loading-unloading cycle conditions are tested into two stages; firstly, one cycle of loading and unloading under each confining pressure $(200,500,800,1200 \mathrm{kPa})$ is conducted, as shown in Figure 8; Secondly, multiple cycles of loading and unloading under each confining pressure (200, $500,800,1200 \mathrm{kPa}$ ) are conducted, as shown in Figure 9. 

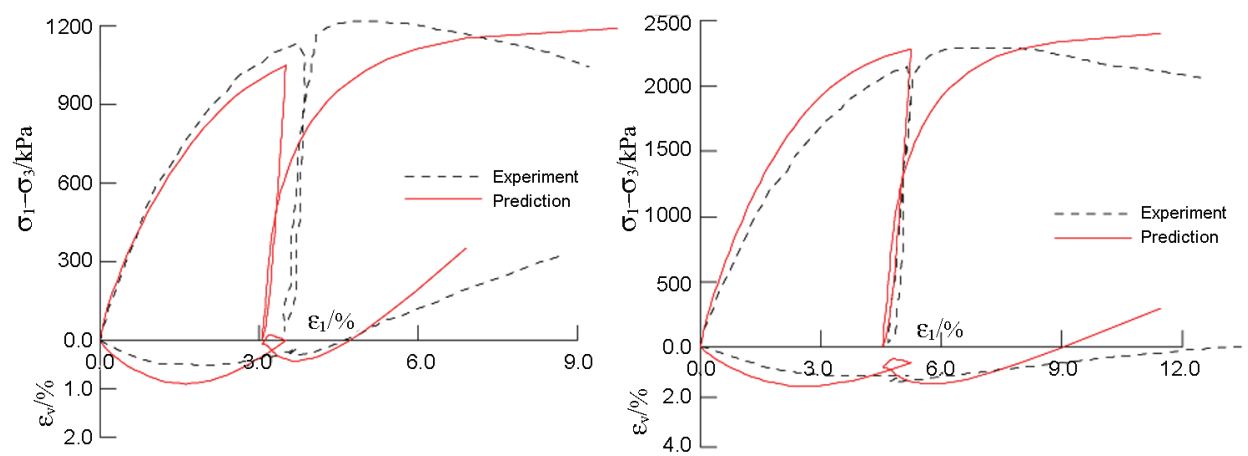

(a) $\sigma_{3}=200 \mathrm{kPa}$

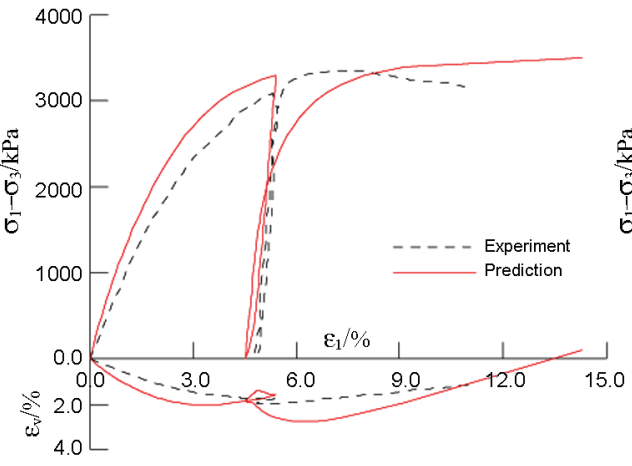

(c) $\sigma_{3}=800 \mathrm{kPa}$ (b) $\sigma_{3}=500 \mathrm{kPa}$

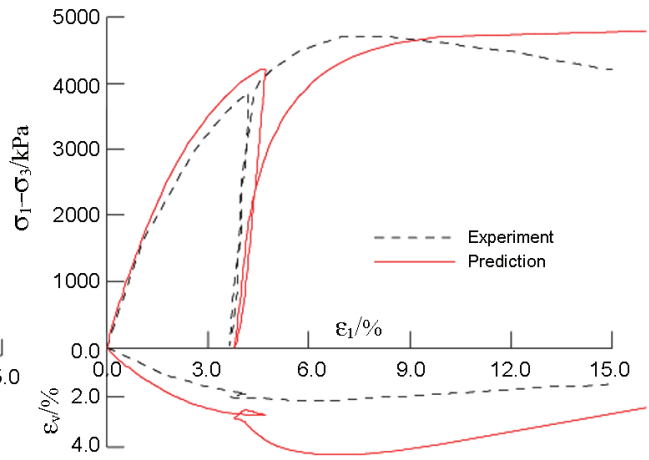

(d) $\sigma_{3}=1200 \mathrm{kPa}$

Fig. 8. One cycle of loading and unloading under each confining pressure

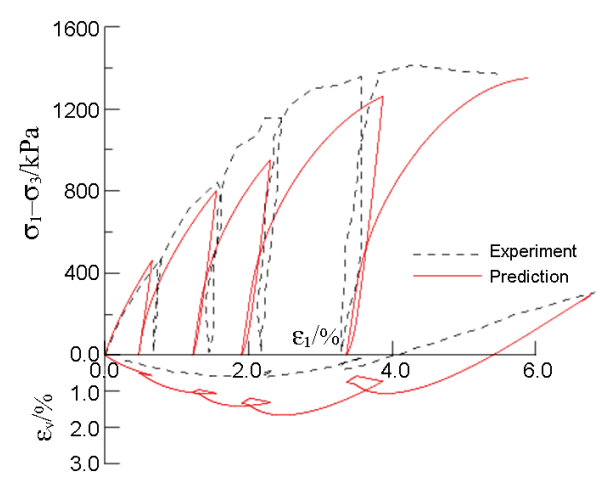

(a) $\sigma_{3}=200 \mathrm{kPa}$

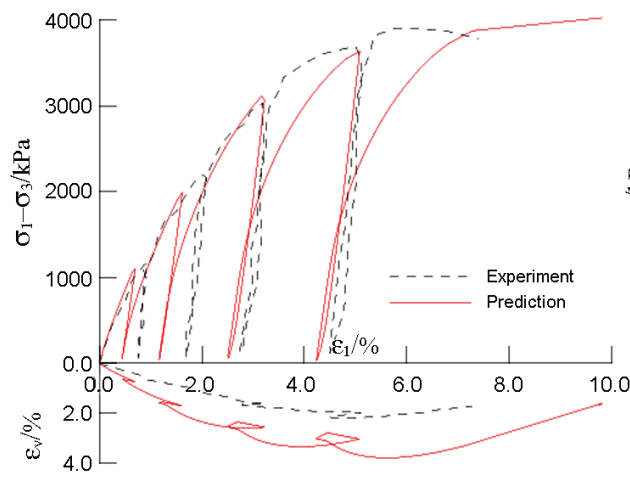

(c) $\sigma_{3}=800 \mathrm{kPa}$

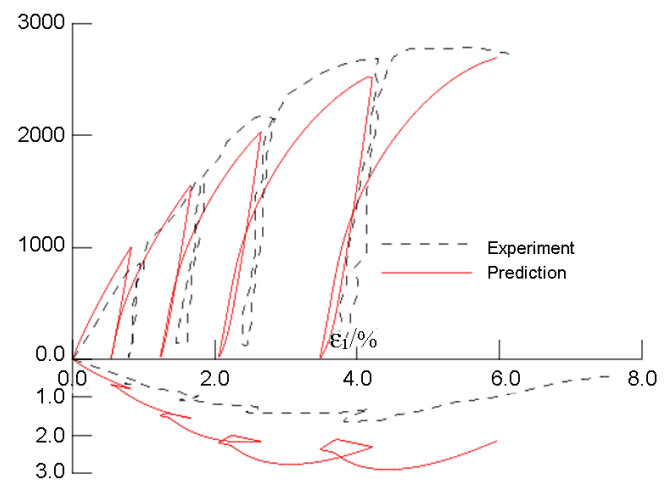

(b) $\sigma_{3}=500 \mathrm{kPa}$

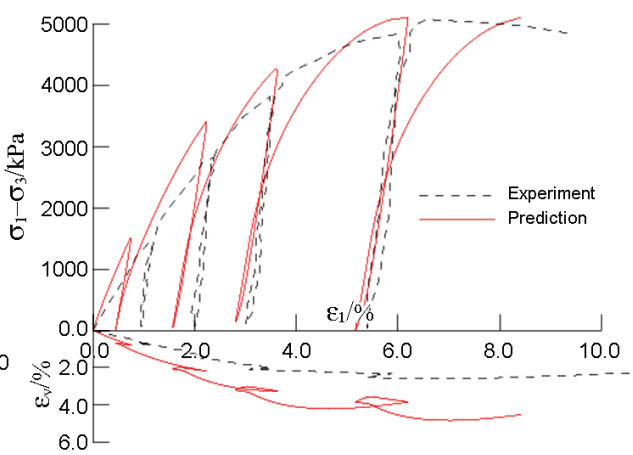

(b) $\sigma_{3}=1200 \mathrm{kPa}$

Fig. 9. Four cycles of loading and unloading under each confining pressure 
It can be seen, constitute model used in this study can predict behaviors of coarse grained soils under loading and unloading cycles well. After adopting the rotational hardening rule, a closed hysteresis loop will form in a loading and unloading cycle, which is agree with the test results. According to test results, samples that experience different loading conditions have different shear strength. Shear strength of each sample is plotted in Figure 4; samples experience loading and unloading cycle tends to have higher shear strength than ones experience monotonic loading.

\subsection{Behaviors of coarse grained soils under repeated shear stress}

Elastoplastic behaviors of coarse grained soils under repeated shear stress with constant $p=1200 \mathrm{kPa}$ are predicted with this model in Figure 10(a) to 10(c). Figure 10(a) presents the relationship of shear stress $q$ and general shear strain $\varepsilon_{s}$. Figure $10(\mathrm{~b})$ shows the increase of volumetric strain; it can be seen, during the first few cycles, volumetric strain increase rapidly and then become almost constant in subsequent cycles. Figure 10(c) shows the change of OC parameter $R$ with general shear strain $\varepsilon_{s}$, which indicates that OC parameter $R$ decreases and soils become denser after repeated shear stress.

Yang et al. (2010) conducted drained cyclic loading tests with weak weathered granite rock-fills at constant mean stress $1400 \mathrm{kPa}$ and maximum deviatoric stress ratio 0.3. Model Parameters are: $c_{t}=0.0045, c_{e}=0.0004$, $m=0.74, M=1.547, p_{c}=3800 \mathrm{kPa}, n=0.11, m_{b}=0.65$, $\alpha=12.0$. Test results and model predictions are compared in Figure 11.

Figure 11(a) presents the relationship of stress ratio $\eta_{d}$ and the first principal strain $\varepsilon_{1}$; Figure 11(b) presents the relationship of stress ratio $\eta_{d}$ and the volumetric strain $\varepsilon_{v}$; Figure 11(c) presents the relationship of $\varepsilon_{1}$ and the cycle number; Figure 11(d) presents the relationship of volumetric strain $\varepsilon_{v}$ and the cycle number. As can be seen, $\varepsilon_{1}$ and $\varepsilon_{v}$ accumulate with increase of cycle number. The rotational kinematic hardening model could describe soil behaviors under cyclic loadings quantitatively.

\section{Application of the rotational hardening model to predict deformation of Shuibuya CFRD}

Shuibuya dam is the highest CFRD in the world currently, was built in Hubei province, China. The Shuibuya dam is $234 \mathrm{~m}$ high and $675 \mathrm{~m}$ long along the crest. The construction of the dam began in 2002 and was completed in 2007. Because the paramount significance of the project, detailed settlement monitoring system was adopted to monitor the deformation of the Shuibuya CFRD. Interior settlement monitoring system (ISMS) was placed in three important cross-sections: $0+132,0+220$, and $0+356$, in which $0+220$ is the maximum cross-section. The layout of the in-situ settlement gauges of cross-section $0+220$ is shown in Figure 12. In this research, measurements of settlement gauges at elevations 235.0, 265.0, $300.0 \mathrm{~m}$ are used to validate the kinematic hardening model (Zhou et al. 2011).

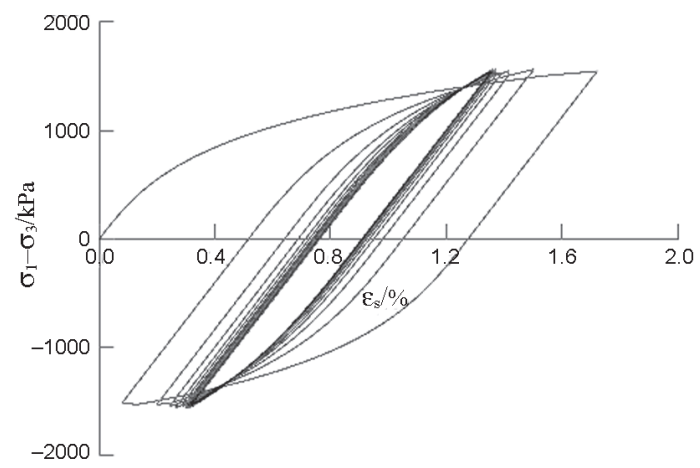

(a) Relationship of $q$ to $\varepsilon_{S}$

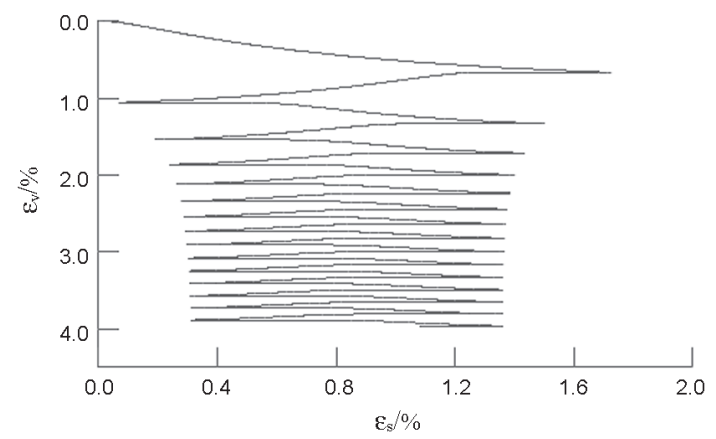

(b) Relationship of $\varepsilon_{v}$ to $\varepsilon_{S}$

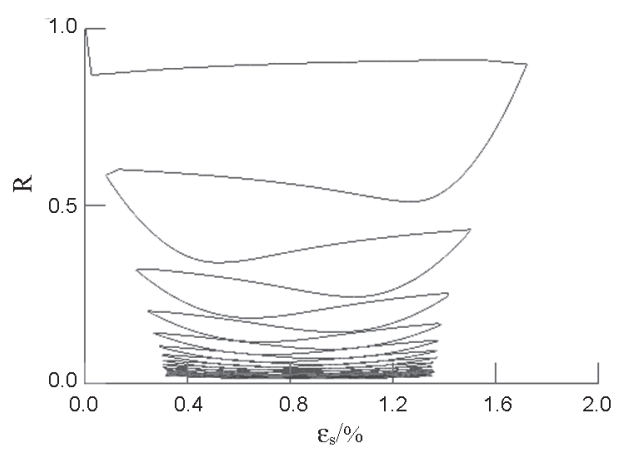

(c) Relationship of $R$ to $\varepsilon_{S}$

Fig. 10. Behaviors of coarse grained soils under repeated shear stress 
The construction process of Shuibuya dam is divided into 33 steps, construction schedule is also marked in Figure 12 within a circle. In the process of dam construction and operation, creep behaviors of rock-fills are also considered with an incremental creep model proposed by Zhu et al. (2011). In this study, concrete slab is simulated as elastic materials with elastic modulus $E=2.1 \mathrm{e} 7 \mathrm{kPa}$ and Poisson's ratio $v=0.3$. Model parameters of main rock-fill (dry density $2.17 \mathrm{~g} / \mathrm{cm}^{3}$ ) and secondary rock-fill (dry density $2.13 \mathrm{~g} / \mathrm{cm}^{3}$ ) are back analyzed from large scale plate-loading tests.

\subsection{Back calculated model parameters from field plate-loading test}

Model parameters that obtained via indoor tests may not reflect properties of the original graded soils, because the original graded soils are usually downsized to prepare for the indoor sample. To overcome this so-called "scale effect", large scale field plate-loading tests were conducted to get model parameters from original graded coarse grained soils, shown in Figure 13(a).

In conducting the back-analysis, one group of parameters needs to be specified to make corresponding calculated and measured settlements the best approximations to each other. This paper used Immune Genetic Algorithm to specify the model parameters (Zhu 2011). Note that strength parameters are assumed to be the same as that obtained via indoor tests. Values of $\alpha$ and $m_{b}$ are taken referencing to weathered granite rock-fills (Yang et al. 2010). Therefore, we need to search for only three parameters: $c_{t}, c_{e}, m$.

As an example, here presents back calculated results of the main rock-fill. Calculated settlement contours of
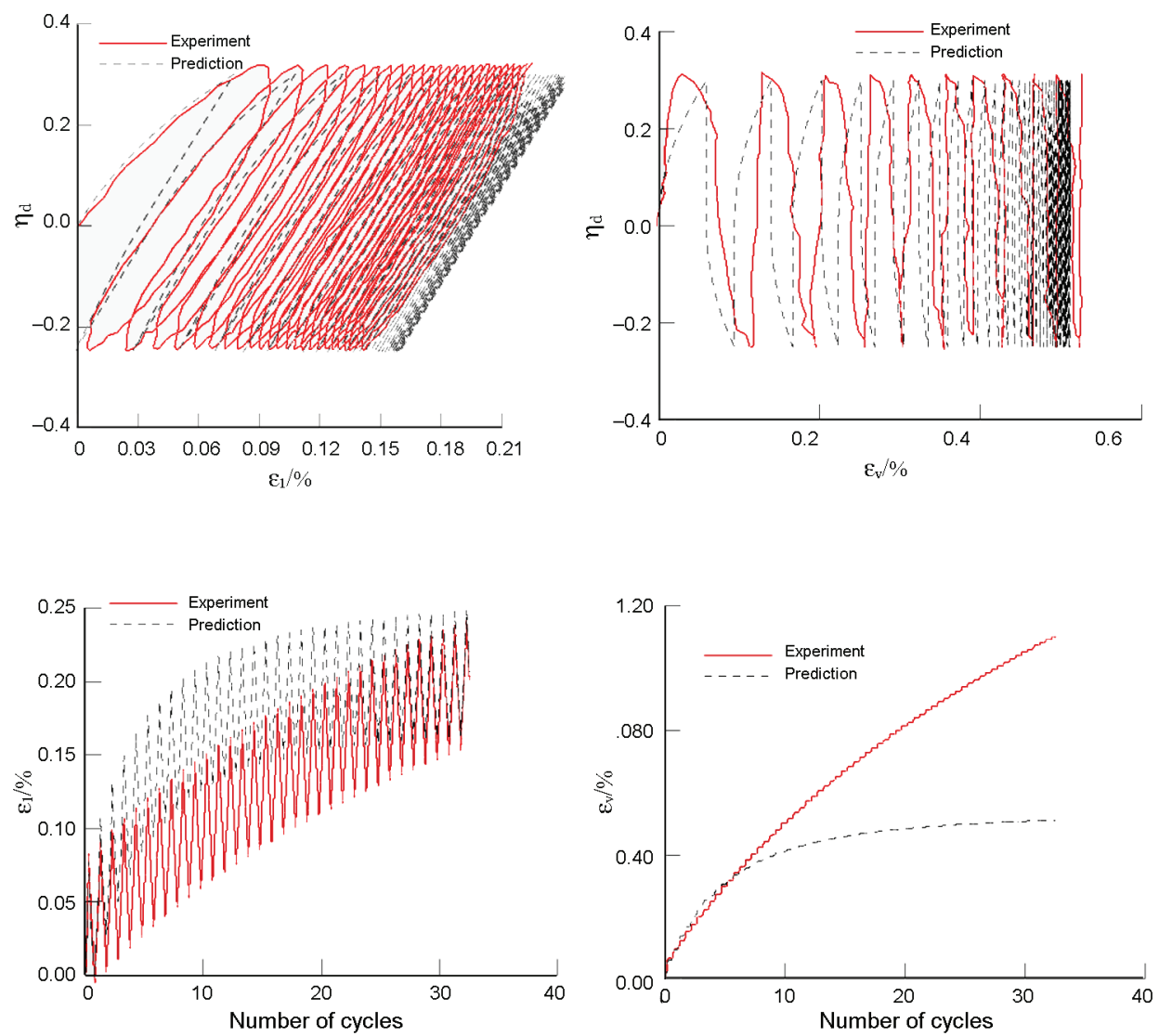

Fig. 11. Cyclic loadings with constant $p=1400 \mathrm{kPa}$ and $\eta_{d \max }=q_{\max } / \mathrm{p}=0$ (Yang et al. 2010)
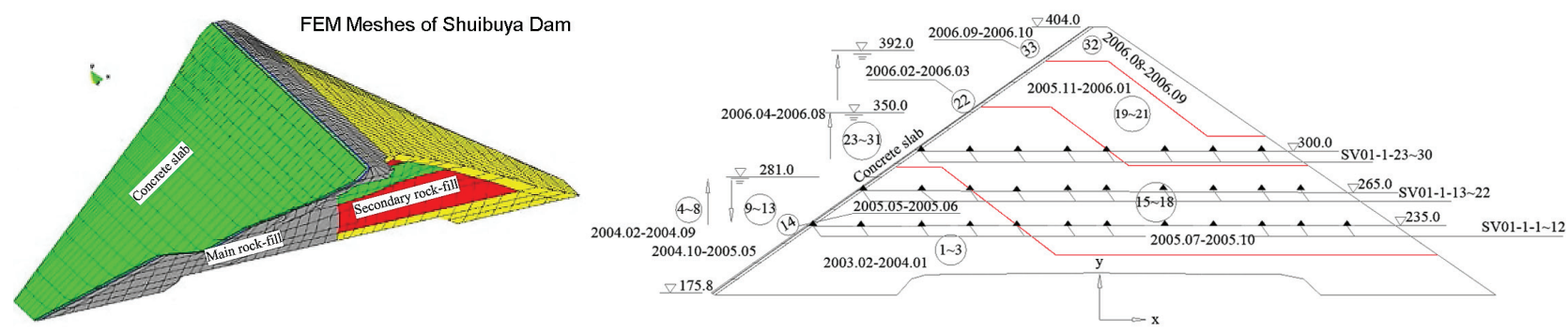

Fig. 12. Positions of ISMS and construction schedule of cross-section $0+220$ of Shuibuya dam 
main rock-fill are shown in Figure 13(b), Calculated $\mathrm{X}$-displacement contours of main rock-fill are shown in Figure 13(c), and Figure 13(d) shows the comparisons between the calculated and measured settlements at the measuring points. As can be seen, calculated and measured settlements are rather consistent at measuring points. Parameters of main rock-fill and secondary rock-fill are both listed in Table 2.

\subsection{Behaviors of Shuibuya rock-fill dam in construction and operation period}

Figure 14 presents the displacement contours of Shuibuya CFRD at the full storage period. It can be seen, the maximum settlement could reach $201.4 \mathrm{~cm}$ at the maximum cross-section $0+220$. Settlements versus time observed by settlement gauges are compared with calculated values in Figure 15 (at each elevation, three measuring points are selected).

These curves indicate that the vertical displacement cumulated over time. During the period of construction (before October 2006), with the continuous raising of the dam, the settlement increased rapidly. Most of the settlement occurs during the construction period. When the

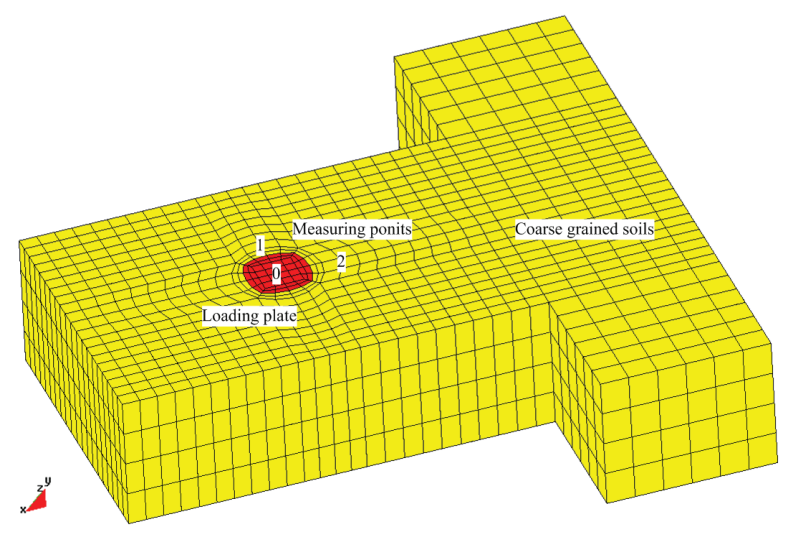

(a) Large scale field plate-loading tests and measuring points

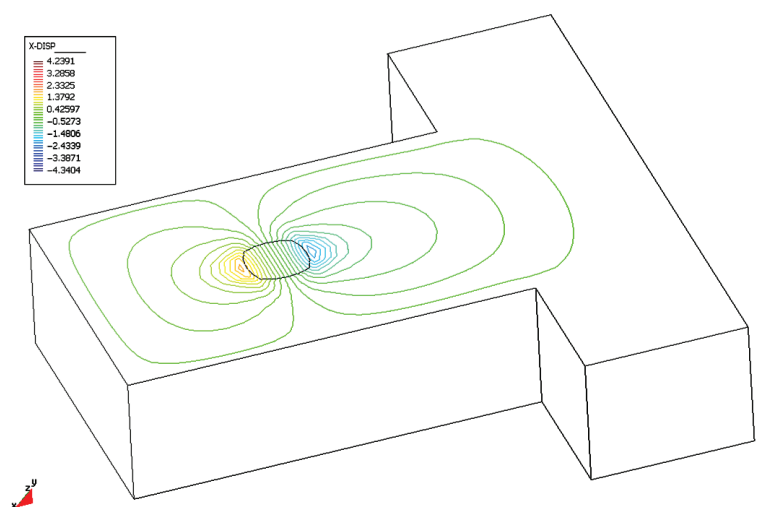

(c) Contours of X-displacement (mm) calculated with FEM reservoir rise, the settlement increases slower than that during construction. Settlements of different elevations at completion period and full storage period are plotted in Figure 16. Results show that the rotational hardening model could give reasonable results for dam behaviors in construction and operation period.

After the full filling of the dam, assume that water level cycles between elevation $350 \mathrm{~m}$ and $392 \mathrm{~m}$, the incremental displacement after five cycles are shown in Figure 17. As can be seen, the rotational kinematic hardening model could simulate the permanent deformation of the CFRD in the process of complex loading conditions. The maximum incremental settlement occurs at the crest of the rock-fill dam. The deflection of the concrete

Table 2. Back analyzed model parameters of the rotational hardening model

\begin{tabular}{lcccccccc}
\hline & $c_{t}$ & $c_{e}$ & $m$ & $M$ & $p_{c} / \mathrm{kPa}$ & $n$ & $\alpha$ & $m_{\mathrm{b}}$ \\
\hline $\begin{array}{l}\text { Main } \\
\text { rock-fill }\end{array}$ & 0.0050 & 0.0010 & 0.70 & 1.64 & 3700 & 0.09 & 12.0 & 0.65 \\
\hline
\end{tabular}

$\begin{array}{lllllllll}\text { Secondary } & 0.0052 & 0.0012 & 0.72 & 1.63 & 3700 & 0.11 & 12.0 & 0.65\end{array}$ rock-fill

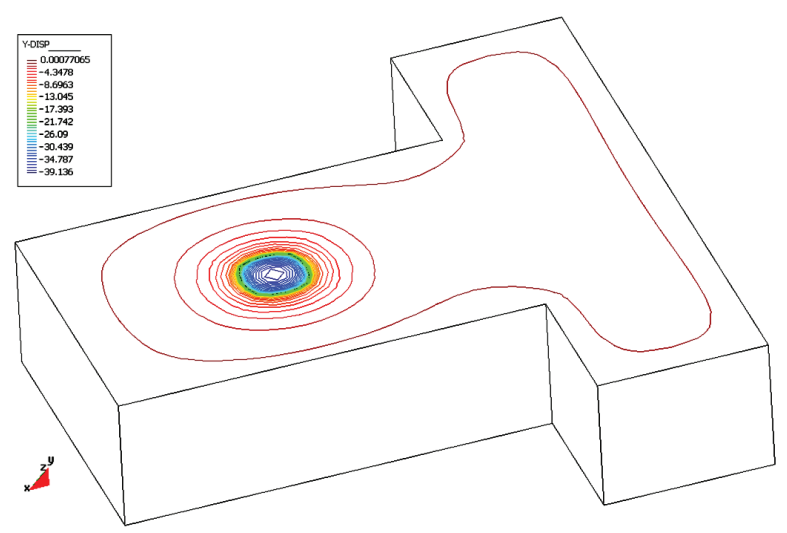

(b) Contours of settlement (mm) calculated with FEM

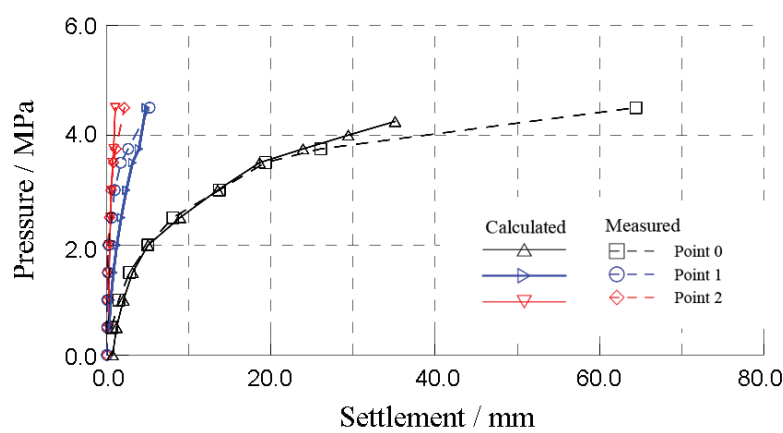

(d) Comparision between the settlement results of measured and back analyzed (main-rock-fill)

Fig. 13. Back calculate material parameters from field plate-loading tests 
slab increases in this process, which may increase the risk of rupture of the concrete slab, therefore, this part of deformation should be considered in dam design.

\section{Conclusions and discussions}

This paper introduced a simplified rotational kinematic hardening model with the concept of "sub-loading", to predict behaviors of Concrete Faced Rock-fill Dam (CFRD) under complex loading conditions. Test results of coarse grained soils were used to validate this model. Results showed that this model could predict mechanical behaviors of coarse grained soils under both monotonic loading and complex loading conditions. Then this model was added to 3D FEM program, to simulate behaviors of Shuibuya CFRD with parameters back analyzed from field plate-loading tests. Computed results are compared

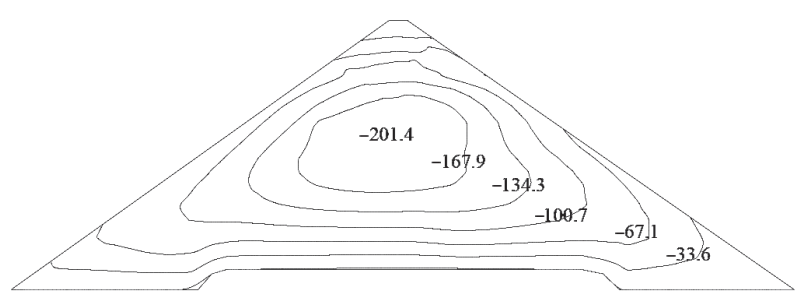

(a) Vertical displacement

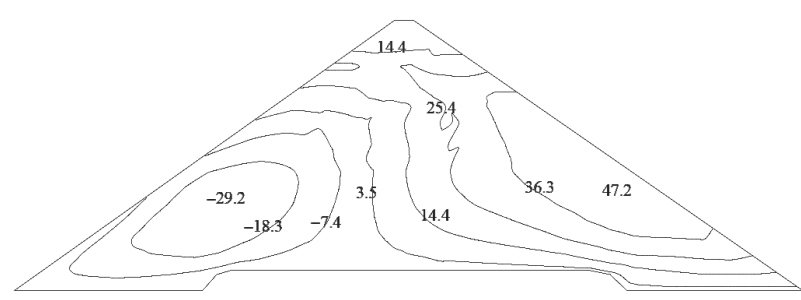

(b) Horizontal displacement

Fig. 14. Predicted displacement contours of the CFRD at full storage period (unit: $\mathrm{cm}$ )

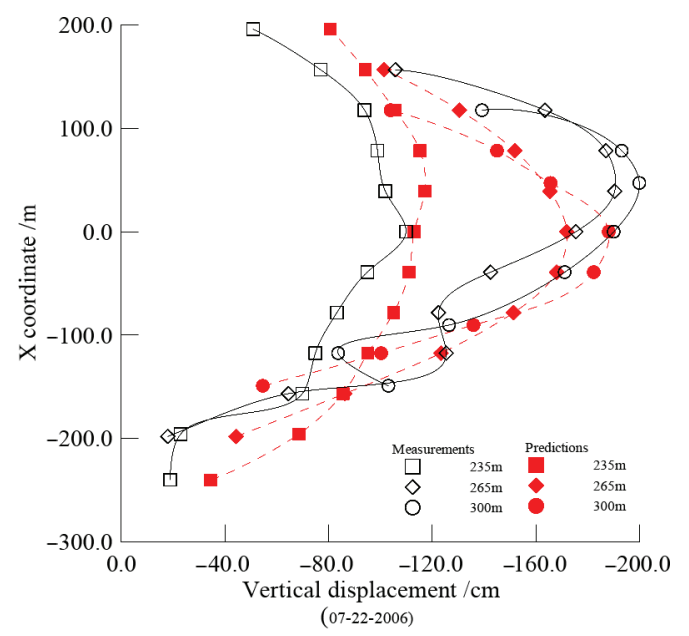

(a) At completion period

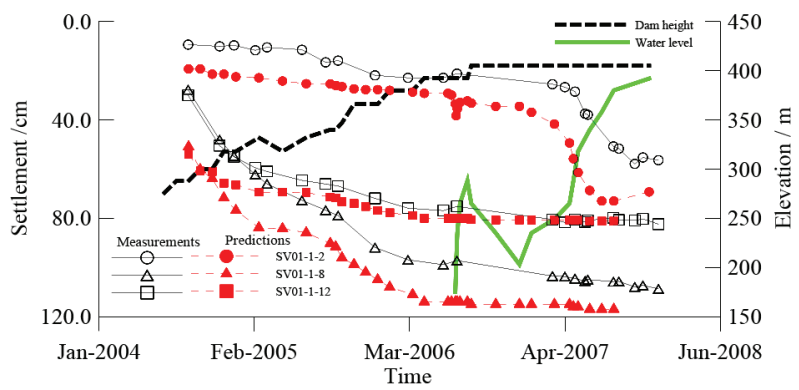

(a) Settlements gauges at elevation of $235 \mathrm{~m}$

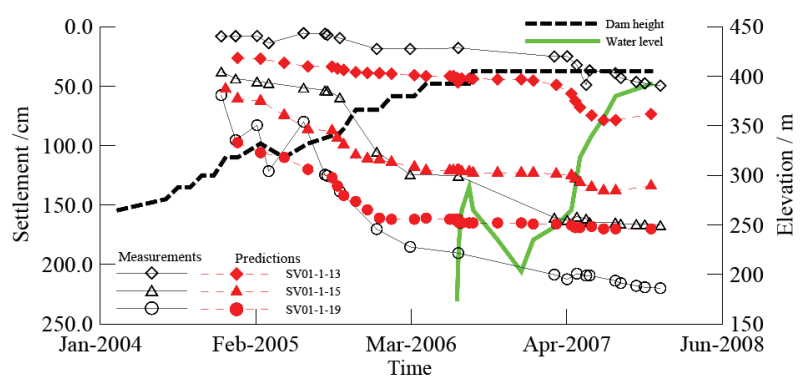

(b) Settlements gauges at elevation of $265 \mathrm{~m}$

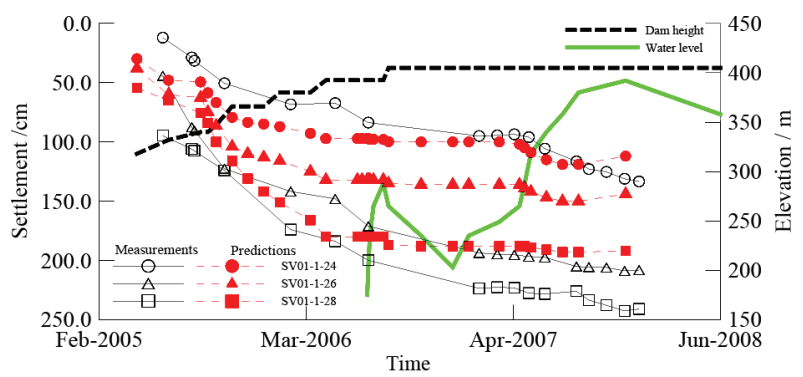

(c) Settlements gauges at elevation of $300 \mathrm{~m}$

Fig. 15. Comparison of settlements between in-situ measured and calculated

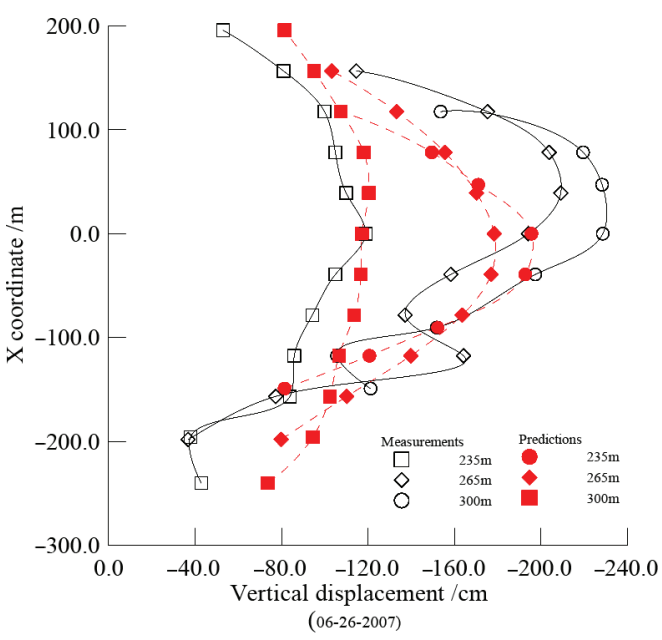

(b) At full storage period

Fig. 16. Comparison of settlements results between in-situ measured and calculated 


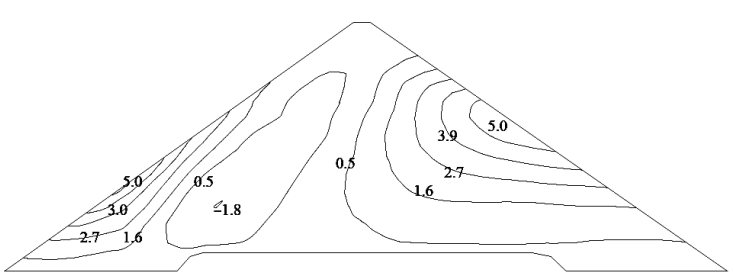

(a) Incremental horizontal displacement contours

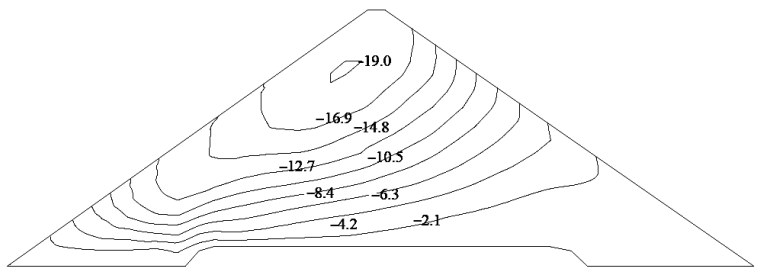

(b) Incremental vertical displacement contours

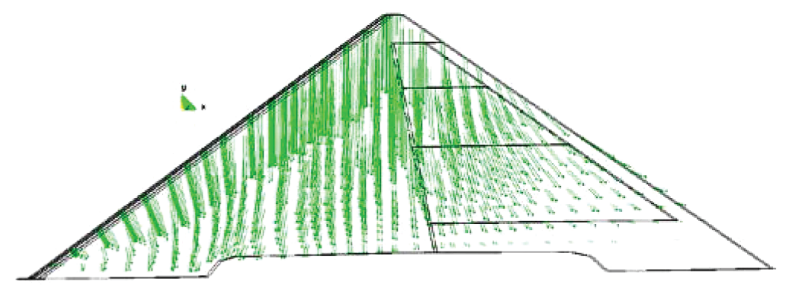

(c) Incremental displacement vectors

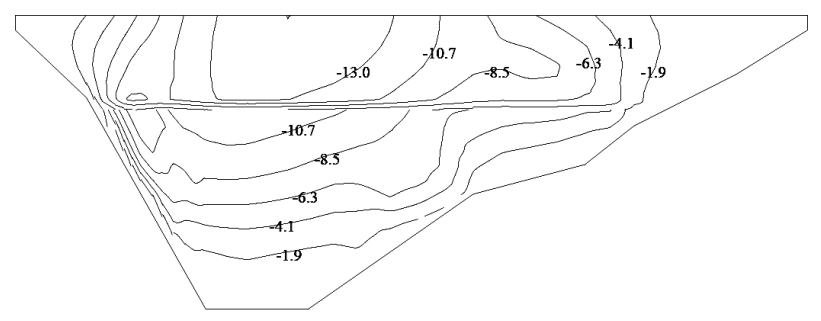

(d) Incremental slap deflection contours

Fig. 17. Incremental displacement contours after five cycles (unit: $\mathrm{cm}$ )

with in-situ measurements. Results showed that, deformation of Shuibuya CFRD during construction and operation period can be predicted with this model. Permanent deformation that caused by fluctuations of water level can be also predicted. With the increase of the number of loading cycles, the OC parameter R decreases, deformation of the CFRD will stabilize gradually.

\section{Acknowledgements}

This work was supported by the National Natural Science Foundation of China (Grant No. 91215301).

\section{References}

Alonso, E. E. 2007. Dilatancy of coarse granular aggregates, Springer Proceedings in Physics 12(3): 19-135. http://dx.doi.org/10.1007/3-540-69873-6_11

Alonso, E. E.; Gens, A.; Josa, A. 1990. A constitutive modelfor partially saturated soil, Geotechnique 40(3): 405-430. http://dx.doi.org/10.1680/geot.1990.40.3.405
Alonso, E. E.; Olivella, S.; Pinyol, N. M. 2005. A review of Beliche Dam, Geotechnique 55(4): 267-285.

http://dx.doi.org/10.1680/geot.2005.55.4.267

Chu, F. Y. 2011. Study on initial anisotropy and its elastoplastic model for coarse-grained soils. PhD Thesis. Hohai University.

Dafalias, Y. F. 1986a. Bounding surface plasticity. I: mathematical foundation and hypoplasticity, Journal of Engineering Mechanics ASCE 112(9): 966-987.

Dafalias, Y. F. 1986b. Bounding surface plasticity. II: application to isotropic cohesive soils, Journal of Engineering Mechanics ASCE 112(12): 1263-1291.

Hashiguchi, K. 1980. Constitutive equations of elastoplastic materials with elastic-plastic transition, Journal of Applied Mechanics 47(2): 266-272.

Hashiguchi, K.; Chen, Z. P. 1998. Elastoplastic constitutive equation of soils with the subloading surface and the rotational hardening, International Journal for Numerical Methods in Engineering 22(3): 197-227.

Hashiguchi, K.; Ozaki, S.; Okayasu, T. 2005. Unconventional friction theory based on the subloading surface concept, International Journal of Solids and Structures 42(5-6): $1705-1727$.

Hashiguchi, K. 2005. Generalized plastic flow rule, International Journal of Solids and Structures 21(2): 321-351. http://dx.doi.org/10.1016/j.ijplas.2003. 12.003

Hashiguchi, K.; Ozakib, S. 2008. Constitutive equation for friction with transition from static to kinetic friction and recovery of static friction, International Journal of Plasticity 24(11): 2102-2124.

http://dx.doi.org/10.1016/j.ijplas.2008.03.004

Inel, S.; Lade, P. V. 1997. Rotational kinematic hardening model for sand. Part II Characteristic work hardening law and predictions, Computers and Geotechnics 21(3): 217-234. http://dx.doi.org/10.1016/S0266-352X(97)00023-2

Lade, P. V.; Inel, S. 1997. Rotational kinematic hardening model for sand. Part I concept of rotating yield and plastic potential surfaces, Computers and Geotechnics 21(3): 183-216.

Nakai, T.; Hinokio, M. 2004. A simple elastoplastic model for normally and over consolidated soils with unified material parameters, Soils and Foundations 44(2): 53-70. http://dx.doi.org/10.3208/sandf.44.2_53

Niemunis, A.; Wichtmann, T.; Triantafyllidis, Th. 2005. A highcycle accumulation model for sand, Computers and Geotechnics 32(4): 245-263.

Pedroso, D. M.; Farias, M. M. 2011. Extended Barcelona basic model for unsaturated soils under cyclic loadings, Computers and Geotechnics 38(5): 731-740. http://dx.doi.org/10.1016/j.compgeo.2011.02.004

Shen, Z. J. 1986. Elastoplastic analysis of consolidation and deformation of soft ground, Science Sinica (A series) XXIX(2): 210-224.

Shen, Z. J. 1994. A new constitutive model for soils, in Proceedings of the $5^{\text {th }}$ Chinese Conference on Soil Mechanics and Foundation Engineering, October 1994, Xi'an, China. Beijing: China Architecture \& Building Press, 101-105 (in Chinese).

Wang, Z. L.; Dafalias, Y. F.; Shen, C. K. 1990. Bounding surface hypoplasticity model for sand, Journal of Engineering Mechanics ASCE 116(5): 983-1001.

http://dx.doi.org/10.1061/(ASCE)0733-9399(1990)116:5(983)

Xu, X. J. 2008. Safety analyzing of dams of the upper and lower reservoirs at Tongbai Pumped Storage Power Station. Master Thesis. Zhejiang University.

Yang, G.; Sun, X.; Yu, Y. Z., et al. 2010. Experimental study of mechanical behavior of a coarse-grained material under various stress paths, Rock and Soil Mechanics 31(4): 1118-1122 (in Chinese). 
Yao, Y.; Gao, Z.; Zhao, J.; Wan, Z. 2012. Modified UH model: constitutive modeling of overconsolidated clays based on a parabolic Hvorslev envelope, Journal of Geotechnical and Geoenvironmental Engineering 138(7): 860-868. http://dx.doi.org/10.1061/(ASCE)GT.1943-5606.0000649

Yao, Y. P.; Hou, W.; Zhou, A. N. 2007. UH model: threedimensional unified hardening model for overconsolidated clays, Geotechnique 59(5): 1-19. http://dx.doi.org/10.1680/geot.2007.00029

Yao, Y. P.; Huang, G.; Wang, N. D., et al. 2011. Stress-strain characteristic and three-dimensional constitutive model of rockfill considering crushing, Industrial Construction 41(9): 12-17.

Yao, Y. P.; Lu, D. C.; Zhou, A. N., et al. 2004. Generalized non-linear strength theory and transformed stress space, Science in China Series E: Technological Sciences 47(6): 691-709. http://dx.doi.org/10.1360/04ye0199

Yao, Y. P.; Wan, Z.; Chen, S. S. 2011. Dynamic UH model considering particle crushing, Chinese Journal of Geotechnical Engineering 33(7): 1036-1044 (in Chinese).
Yao, Y. P.; Yamamoto, H.; Wang, N. D. 2008. Constitutive model considering sand crushing, Soils and Foundations 48(4): 603-608.

Zhang, F.; Ye, B., et al. 2007. Explanation of cyclic mobility of soils: approach by stress-induced anisotropy, Soils and Foundations 47(7): 635-648.

Zhou, W.; Hua, J. J.; Chang, X. L.; Zhou, Ch. 2011. Settlement analysis of the Shuibuya concrete-face rockfill dam, Computers and Geotechnics 38(2): 269-280. http://dx.doi.org/10.1016/j.compgeo.2010.10.004

Zhu, S. 2011. Back analysis on construction and operation properties of Shuibuya concrete face rockfill dam, Chinese Journal of Rock Mechanics and Engineering 30(2): 3689-3695 (in Chinese).

Zhu, S.; Wang, Y. M.; Xu, Q. 2011. Study of incremental rheological model of coarse grained material for embankment, Rock and Soil Mechanics 32(11): 3201-3206 (in Chinese).

Kuangmin WEI. Was born in 1985 in Gansu province of China, PhD of Hohai University, worked at Nanjing Hydraulic Research Institute. Several articles are published in journals, books, and proceedings. He is interested in constitutive model and elastoplastic theories in geotechnical Engineering. In recent years, elastoplastic models (e.g. bounding surface model, rotational hardening model, generalized plasticity model, etc.) to predict mechanical behaviors of soil under complex loading conditions are studied in detail.

Sheng ZHU. Was born in 1965 in Hunan province of China. PhD, Professor of Hydraulic Structures in Hohai University, institute of hydraulic structures. He has published more than 40 articles in journals, books, and proceedings. Many results are successfully used in dam construction. His research interests include: mechanical properties of coarse grained soils under complex loadings, time-dependent properties of coarse grained soils, constitutive model of soils, and seismic analysis of rock-fill dam etc. His group is also involved in the construction of Shuibuya rock-fill dam, which is the highest Concrete-Faced Rock-fill Dam in the world. 